\title{
0 Jornal do Brasil e as noções de tempo histórico no fazer jornalístico
}

\section{RESUMO}

Este artigo tem como objetivo a análise das noções de tempo implicadas nas narrativas que o Jornal do Brasil produz acerca de sua história na sua edição centenária de 1991. Com isso, pretende-se investigar que tipo de expectativa estava em jogo nas práticas jornalísticas no Rio de Janeiro. A principal hipótese é que o jornal articula uma capacidade de previsão a partir de um capital simbólico ancorado na sua trajetória.

\section{PALAVRAS-CHAVE}

Jornal do Brasil

narrativa

temporalidade

\section{ABSTRACT}

This article aims at the analysis of the concepts of time involved in narratives produced by Jornal do Brasil concerning its own history in the centenary issue in 1991. This is intended to investigate what kind of expectations about journalistic practices were experienced in Rio de Janeiro at that time. The main hypothesis is that the newspaper articulates a forecasting skill based on its symbolic capital anchored to its trajectory.

\section{KEY WORDS}

Jornal do Brasil

narrative

temporality

\section{Letícia Matheus \& Marialva Barbosa UFF \\ leticia_matheus@yahoo.com.br\&mcbl@terra.com.br}

A edição do centenário. "O velho e o novo". O título do encarte especial da edição centenária do Jornal do Brasil sintetiza as principais idéias desenvolvidas no editorial de primeira página pelo então diretor, Manoel Francisco do Nascimento Brito.

A comparação entre passado e presente é, grosso modo, a linha condutora das narrativas que vão surgindo nas 40 páginas sobre a história do jornal e que ajudam a perceber as representações do fazer jornalístico ao longo de um século.Se é próprio dos jornais uma prolixia sobre o mundo, por outro lado, o falar da própria atividade é mais escasso, como na edição comemorativa. Ela pode ser entendida como renovação de pacto com o público leitor, como quando destaca os principais pontos de venda ou quando perfila seu público assinante. Ao exibir as opções políticas, as considerações sobre a mídia, o comportamento social de seu leitor, o JB estava falando ao mesmo tempo dos seus posicionamentos. Estava reforçando sua identidade e seu papel em meio a outros meios de comunicação ("jornal com mais qualidade, à frente de rádios, revistas e televisão"). Segundo Barbosa (2007), a escolha de uma data para se comemorar constitui uma estratégia memorável em torno da qual se elaborará uma sociabilidade (em torno do jornal) e uma pedagogia (sobre como usá-lo). Nesse sentido, as datas podem ser consideradas monumentos de memória. Mas o que o JB está de fato comemorando 1891 ?

\section{A construção temporal}

O editorial e os artigos recortam a história do Jornal do Brasil em quatro fases: uma "origem" estendida, que representa, na cronologia dessas narrativas, os 60 anos anteriores à década de 50; "a reforma", que significa o período de transição para um novo jornalismo e para o qual não se estipulam marcos iniciais nem finais; os anos 60/70, quando o jornal se tornaria expressão de resistência em favor da liberdade; e finalmente a década de 80 , em que o JB se estabilizaria como promotor da justiça. Este não é um dado insignificante se temporalidade for entendida como "o modo de inscrição da ação humana na duração" (BARBOSA, op. cit., p. 52). Nesse sentido, estudar as relações com o tempo é perceber as noções de historicidade de um conjunto de homens em um dado momento. Essa temporalidade na qual estão imersos, ou intratemporalidade para Heidegger, ou arquitetura temporal para Pomian (1984), é expressa nas construções narrativas.

Ainda que involuntárias, a segmentação e classificação da história de qualquer coisa em fases podem ser entendidas já como um modo de interpretação. Na escolha dos temas dos artigos e do editorial, e no tratamento 
década-a-década dado à história do Brasil, o Jornal do Brasil cria uma certa noção de tempo, com algumas fases. As principais são o velho e o novo JB, tendo entre um e outro o marco divisor: a reforma.

\section{0 corte}

Nem sempre o Jornal do Brasil fala de si de modo coerente. Existe tanto um problema de referência temporal quanto de atribuição de intencionalidades na produção dessas narrativas. Os dois problemas estão imbricados. Em relação ao primeiro, embora, no editorial, Nascimento Brito localize o desencadear da reforma 34 anos antes, ou seja, em 1957, o segundo artigo, "A reforma", assinado por Moacyr Andrade, começa assim: "A reforma do JORNAL DO BRASIL não teve número zero. O que a caracteriza em primeiro lugar é o andamento gradativo." Ou seja, o principal marco histórico apresentado pelo JB não tem data certa para começar nem para terminar, o que já é significativo do que se pretende com isso.

Esse corte temporal estendido, gradual, é chamado de "a reforma" ao longo da maior parte da edição mas se caracteriza por muito mais que um conjunto de mudanças gráficas. Trata-se de uma intensa discursividade que se produziu pós-anos 50 acerca do jornalismo no Brasil. Segundo Silva (2007), uma geração de importantes jornalistas se esforçou em construir discursivamente a idéia de que os anos 50 inauguraram o que seria o moderno jornalismo brasileiro, sobretudo a partir da definição de critérios identitários em torno da questão da profissionalização.

A cada narrativa desta edição, pressente-se um subtexto iminente que diria: Foi o JB que desencadeou a modernização da imprensa no Brasil. Em vários outros momentos, entretanto, a relevância do JB é ressaltada explicitamente: “...o segundo (artigo) tem como tema a reforma editorial que revolucionou o jornalismo brasileiro." (JB, 07/04/91, primeira página.)

O mais importante é perceber que esse discurso dos anos revolucionários foi construído a posteriori, nos anos 80 , a partir de disputas bastante concretas, inclusive sindical, entre duas gerações de jornalistas em torno dos critérios de profissionalismo que se pretendia desenhar. (SILVA, op. cit., p. 65) O problema da objetividade, por exemplo, surge quando Brito, que é da geração acusada de romântica, diz que antes de ser notícia, um jornal é opinião, "não adianta tergiversar. Jornal sem opinião é omissão." (JB, 07/04/91, primeira página). Andrade elenca no artigo os principais componentes desse processo de reforma: gradativa mudança gráfica, editorial e industrial, com a compra de novas rotativas, a criação de texto-legenda, uma seção exclusiva de esportes e de outra feminina, a mudança no projeto gráfico realizado pelo artista plástico Amílcar de Castro, a retirada de parte dos classificados da primeira página, restando apenas um " $L$ " do canto superior esquerdo até o canto direito do rodapé, além da criação de um setor de pesquisa e do famoso Caderno B.
O "não-começo" e o "não-fim" que caracterizam a descrição da reforma podem ser considerados a principal senha de compreensão do velho e o novo para o JB, que consegue, assim, reificar narrativamente seu poder em 1991, tendo a reforma como grande patrimônio. Ele sugere que sua transformação foi conseqüência das necessidades da sociedade. Se tudo se transformava, por que não o jornalismo?

Na segunda metade do século tudo haveria de ser novo, como o cinema que se passou a fazer. A música rotulava-se de Bossa Nova. Nova, em breve, seria a capital. A poesia também era neo, neoconcretista. O futebol, velha paixão, renovava-se para alcançar pela primeira vez a culminância do título mundial. (JB, 07/04/91, página 5)

O único momento da edição em que a idéia de reforma é problematizada é no editorial. Nele, Brito diz preferir o termo modernização, explicitando um sentido que já estava embutido, e que capitaliza ainda mais relevância para o JB em referência àquele momento. Associando a reforma a uma conseqüência "natural" (palavra dele) do momento histórico que vivia o Brasil, o diretor sugere que qualquer outro veículo de comunicação teria tomado frente nisso que ele chama de atitude de modernização e que o fato de o JB ter desencadeado o processo foi apenas circunstancial, devido ao fato de ele estar preparado financeiramente para os novos tempos.

Não atribuo ênfase ufanista à reforma do JORNAL DO BRASIL, que, vista de longe, tem o halo lendário das iniciativas que dão certo. Não foi, entretanto, vontade pessoal nem projeto empresarial. Foi muito mais o produto de circunstâncias, entre as quais sobressaem a situação financeira da empresa, com hegemonia no mercado de anúncios classificados, ausência de dívidas e um nome honrado para valorizar a transformação. (JB, 07/04/91, primeira página)

Existe aí uma tensão entre uma falsa modéstia e o sentido que está sendo explicitado que é o da noção de necessidade, como se houvesse um embrião de novo jornalismo esperando sua maturação e manifestação que se dariam com o simples passar do tempo. Ou seja, haveria uma espécie de modernidade latente.

Mas essa concepção deriva de uma historiografia vulgar é pensar que o tempo passa, quando, de fato, somos nós, narradores da vida, que o fazemos passar. (RICOEUR, 1994) Tal concepção deriva da fundamentação fenomenológica de tempo evidentemente, contra a idéia de tempo cósmico.

Apresenta-se, então, o problema de verossimilhança no plano da coerência nas intenções. Para isso, traz-se a questão do autor, do narrador-protagonista e do acontecimento. Quem é o autor do jornal? Quem narra os cem anos do Jornal do Brasil? Certamente, o JB não é uma 
entidade auto-enunciativa. Um grupo de profissionais escreve por ele (Brito, Andrade, Ventura, todos os repórteres, redatores, fotógrafos etc), assumindo a funçãoautor-Jornal-do-Brasil. Essa autoria não é plenamente homogênea, com uma total identificação entre a política editorial dos donos da empresa e os funcionários que escrevem, mas uma composição de fluxos narrativos, inclusive dos leitores. Dessa ordem discursiva, na qual os indivíduos exercem papéis enunciativos, resulta o jornalismo praticado pelo JB. (FOUCAULT, 2000)

Então, uma das primeiras concordâncias narrativas produzidas nesta edição parte do efeito de autoria única em torno do título "Jornal do Brasil", embora tantos sujeitos tenham falado por meio dele em cem anos. Ou seja, um dos efeitos de unicidade narrativa com a qual se preocupava Aristóteles se dá pela função autor. Nesse caso, a edição centenária pode ser entendida como construção em retrospectiva da obra desse autor-JB.

Ainda contra um totalitarismo enunciativo, recorre-se freqüentemente aos conceitos de polifonia e dialogismo de Bakhtin (1992), para desmontar a pretensa autonomia dos indivíduos em relação ao contexto históricosocio-cultural. Entretanto, mesmo diante da complexidade de suas obras, esses autores trabalham um conceitodiscurso - que corre o risco de ser compreendido simplisticamente, mesmo quando adotado o problema da enunciação. $\mathrm{O}$ conceito de discurso acaba não favorecendo tanto a aproximação com a história do que o de narrativa. Isso porque, na narração, a representação é um agir mais nitidamente posto no plano temporal. Assim, ao se introduzir o problema do tempo, destaca-se o caráter processual da comunicação e as implicações da representação no processo histórico.

Daí a escolha por Paul Ricoeur. Seu conceito de tríplice mímese deixa nítida a natureza processual da comunicação e sua concepção ficcional de toda narrativa fornece uma ruptura epistemológica que ajuda a minar a base de legitimidade de uma série de "gêneros" ou "ordens discursivas" (para lembrar Bakhtin e Foucault) que se apóiam em uma relação pretensamente linear de referencialidade, como muitas vezes se evoca em relação ao jornalismo.

Voltando ao problema da verossimilhança e compreendendo, como Ricoeur (ibidem, p. 280), que, na composição de uma história, instituições podem assumir a função de personagens, percebe-se que o Jornal do Brasil é protagonista de suas narrativas especiais. Mas não só ele. Às vezes, suas narrativas configuram outro protagonista: uma "entidade de primeira ordem do conhecimento histórico" (idem, ibidem, p. 274): a sociedade. Essas entidades, que assumem funções discursivas, são postas em relação "artificialmente" a partir de uma lógica probabilística que é a própria composição da intriga, ou seja, a faculdade de imaginar possibilidades históricas e escolher algumas para construir as relações causais, a coerência narrativa, a verossimilhança.

O terceiro ponto referente à composição do verossímil nessas narrativas é a construção do acontecimento. Podese entender verossimilhança como a composição da concordância dentro de uma obra. Entretanto, a história não avança se não houver peripécias, os acontecimentos, ou seja, a discordância que a faça avançar. Nesse sentido, o jornalismo pode ser encarado como um sistema de produção de discordâncias que ele mesmo sintetiza, produzindo concordâncias. Suas narrativas são sínteses do cotidiano e a edição centenária síntese de cem anos de história. Nela, os acontecimentos eleitos são todas aquelas peripécias narradas de modo a fazer avançar a história, por exemplo, a reforma. Aqui já é possível refletir sobre a intencionalidade atribuída ao processo histórico. Dentre as possibilidades do que poderia ter ocorrido, $\mathrm{o}$ que foi eleito pelo JB para "acontecer"? Quem foi responsável pelo acontecimento? Por que o fez acontecer? Como o jornal se explica?

Brito relata as mudanças técnicas, no início textuais e de diagramação (eliminação de fios entre as colunas, uso de fotografias grandes etc), depois gráficas e comerciais, mas destaca principalmente uma fundamental mudança de caráter editorial: a sensibilização para as questões, valores e expressões de um agente histórico cada vez mais poderoso - a classe média. $O$ diretor diz que morreram as empresas jornalísticas que não tiveram a sensibilidade para perceber os novos tempos - a crescente industrialização, o caráter comercial da imprensa como veículo publicitário, e, sobretudo, a transformação do perfil sócio-econômico da população brasileira. Fica clara sua percepção de que uma determinada classe se expandira na metade do século tanto numérica quanto simbolicamente quando diz:

Despertava uma nova classe média, antes constituída de funcionários públicos e empregados de serviços. A classe média passou a fazer a opinião pública sem se dar conta, como o personagem de Molière que fazia prosa sem saber e se espantou quando soube. A classe média, quando percebeu, começou a fazer um novo Brasil. (JB, 07/04/91, primeira página)

A interpretação desse suposto crescimento e dessa sintonia com classe média nos anos 50 pode ser entendida como uma percepção, nos 90 , do estabelecimento de um novo modelo de consumidor, de um novo agente histórico que se fortalecera naquelas últimas décadas de industrialização. Para Brito, os jornais que eram muito mais afinados com o funcionalismo público e com políticos, e que não perceberam as mudanças a tempo de se reformularem faliram antes mesmo do período militar. Essa é, na verdade, uma das explicações que vão aparecer no artigo da página 7, assinado por Zuenir Ventura, para a sobrevivência do JB. Ou seja, uma atitude tomada no passado, talvez mesmo inconsciente, foi interpretada, em 1991, como conseqüência necessária de uma série de fatos, de uma maneira quase teleológica, como se 
houvesse um modelo inevitável de moderno jornalismo, do qual o JB seria o expoente. De acordo com o raciocínio, a reforma seria inevitável porque o jornal soube acompanhar as transformações do país. Quanto maior a simultaneidade dos tempos da história e do jornal, maiores a chances de sobrevivência.

O problema da causalidade histórica é inesgotável. Collingwood (199?) descreve como se chegou a compreender a "necessidade histórica", identificando em Tácito (55 d.c.) as primeiras tentativas de dar explicações aos acontecimentos, mas atribuindo suas causas à vontade pessoal dos imperadores. Mais tarde, o cristianismo produziu uma reorientação temporal ao adotar uma concepção cronológica de história, mas, neste caso, ainda se atribuía demais as causas às arquitetações divinas. No Romantismo (séc. XVIII), surge a concepção de história como progresso, no sentido de melhoramento da humanidade via educação e uso da razão. Mas foi no final do século XIX que a idéia de progresso se torna um "artigo de fé".

Esta concepção era pura metafísica, extraída do naturalismo evolucionista e impingida à história pela índole da época. Tinha as suas raízes, sem dúvida, na concepção setecentista de história como progresso da raça humana na racionalidade e em direção à racionalidade. (COLLINGWOOD, op. cit., p.229)

A interpretação de Brito de que qualquer outro veículo teria feito o mesmo nas mesmas condições não soa como lei de causalidade? E, como lei, não poderia se repetir nas mesmas circunstâncias em outro lugar e momento? Que tipo de relação de causalidade está em jogo nessas explicações? Parece que, pela quantidade de fatores enumerados, recorreu-se mais a condições necessárias do que suficientes, o que tornaria o vínculo de causalidade ainda mais estreito e, portanto, mais determinista. De qualquer forma, a reforma é construída narrativamente como um acontecimento único na história do JB. É sua grande peripécia.

\section{Condensação do passado}

Coube a Benício Medeiros assinar o artigo sobre o desconfortável passado de um Jornal do Brasil monarquista e "popularíssimo". O único aspecto que poderia ser glamourizado desse passado seria a epopéia da fundação de um periódico naqueles tempos. Intitulado "A origem", na página 3 , o artigo é também um bom exemplo de vestígio de uma era na qual domina a lógica do indivíduo subjetivado. O JB é comparado a uma pessoa que passou por crises de personalidade mas que acabou "se encontrando" conforme amadureceu. Deste modo, todas as opções do período pré-50 consideradas equivocadas em 1991 são atribuídas à imaturidade.

Entre as opções consideradas erradas estão o período monarquista ("...depois serenou e tornou-se adepto apenas da legalidade e do bom senso") e a chamada fase pragmática em que os donos, Fernando e Cândido Men- des de Almeida, tentaram fazer com que o jornal se restabelecesse após os prejuízos pelo fechamento de um ano e 45 dias depois do enfrentamento com o presidente Floriano Peixoto, em 1893.

O relato da fase que consolidou o JB soa como pedido de desculpas e merece umas poucas linhas: "Nessa época, o JORNAL DO BRASIL mereceu o apelido de O popularíssimo, por dar ênfase às reportagens policiais e manter um pé no sensacionalismo. De qualquer forma, aproximou-se do povo." (JB, 07/04/91, página 3, grifo original) Embora esse período não tenha sido muito longo em relação à trajetória do jornal, é um de seus grandes silêncios, mas não o maior. Os quase 40 anos de história (de 1918 a 1957) não são narrados em nenhum momento textualmente. Todo esse período, que inclui a Era Vargas, só aparece em imagens nas páginas ilustradas na segunda metade da edição e rapidamente na menção, da página 7 , aos apoios à posse do vice-presidente João Goulart e à política externa independente do ministro de Jânio Quadros, San Thiago Dantas. Posições aliás, consideradas errôneas pelo jornal em 1991.

Fase ainda mais curta que a do "pé no sensacionalismo" mas não tão velada narrativamente são os primeiros dois anos do jornal, que nasceu para defender a Monarquia. Entrelaçando a vida da República com a do $\mathrm{JB}$, como dois irmãos que nasceram quase ao mesmo tempo e que brigavam muito, o artigo afirma que o JB passou naquele momento por uma crise de crescimento mas a superou graças a seu caráter (outro vestígio do indivíduo burguês psicologizado), conseguindo manter a coerência. Já a República, que também estava em crise em seus primeiros anos, continuava assim, segundo o $\mathrm{JB}$, cem anos depois.

Há outros dois aspectos a serem explorados na narração dessa longa origem estendida que são as idades dos fundadores da empresa (Rodolfo Dantas, 37 anos, Joaquim Nabuco, 42, José Maria da Silva Paranhos, o Barão do Rio Branco, 46) e a idéia de um esforço de superação do seu tempo. Referidas a 1891, as idades significaram, para o JB em 1991, o signo da juventude empreendedora, como se esses sujeitos representassem a antecipação do futuro, ou como diz Koselleck (2006, p. 317), a não-contemporaneidade do contemporâneo.

Esse modo de pensar é perfeitamente possível dentro de uma lógica temporal do progresso que surgira a partir de um grande conjunto de experiências inéditas desde o final do século XVI, como a revolução copernicana, o descobrimento do globo terrestre e o de populações com diferentes modos de organização, o que foi compreendido como diferentes fases de desenvolvimento.

Um grupo, um país, uma classe social tinham consciência de estar à frente dos outros, ou então procuravam alcançar os outros ou ultrapassá-los. Aqueles dotados de uma superioridade técnica olhavam de cima para baixo o grau de desenvolvimento dos outros povos, e quem possuísse um nível superior de 
civilização julgava-se no direito de dirigir esses povos. (Idem, ibidem, p. 317)

Além da idade, destacou-se a energia dos jovens na empreitada da fundação do jornal diante das dificuldades tanto políticas quanto técnicas. Brito por exemplo lembra, em tom de confissão, que a impressão do JB não era muito boa, na verdade, até a década de 50 e que isso vinha sendo negligenciado inclusive dos anais da reforma. História, portanto, que ele corrige.

A primeira carta de Nabuco não veio a tempo de sair no primeiro número, porque o vapor atrasou. O equipamento moderno encomendado à prestigiosa Casa Marinoni, na Europa, também não chegara (...). Na falta de melhor equipamento, o primeiro JB foi impresso numa Alauzet-Express, plana, que entrou em operação às 11 da noite. A luz mortiça do gás acetileno iluminava a oficina, de onde começou a sair um barulho que, àquela hora morta, tomou conta da Gonçalves Dias. (JB, 07/04/91, página 3, grifo original)

\section{Presente contínuo}

Já que se falou em luz mortiça, o terceiro artigo fala das trevas. Se a reforma dos anos 50 é entendida como um processo, os anos 60 e 70 são narrativamente configurados como sua ameaça de pausa. Como o jornal manteve a missão de revolucionar a imprensa durante o período militar? Segundo o artigo da página 7, assinado por Zuenir Ventura, foi justamente no período mais movimentado e rico da sua história que o Jornal do Brasil consolidou a reforma, nos anos 60 e 70, prova de fogo da qual a empresa saiu vitoriosa. Além disso, há, mais uma vez, o entrelaçamento entre o jornal e o Brasil.

Depois de realizar, no fim dos anos 50, uma reforma cujos efeitos se espalharam aos poucos por toda a imprensa brasileira, oJORNAL DO BRASIL, para consolidá-la, viveu nas duas décadas seguintes alguns dos momentos mais ricos e agitados de sua história - $a$ exemplo, aliás, do que ocorreu como país e o mundo. Graças às conquistas anteriores, que o lançaram na modernidade editorial, técnica e industrial, ojornal pôde acompanhar os saltos e sobressaltos que marcaram a trajetória do Brasil e do planeta nos anos 60 e 70. (JB, 07/04/91, página 7, grifos nossos)

Ventura apresenta a imprensa como uma instituição impotente frente ao poder repressivo da ditadura, mas ainda assim como um foco possível de resistência, sobretudo frente à TV, o que sugere mais uma vez uma tentativa de o JB se afirmar não somente em relação aos demais periódicos mas também aos meios de comunicação em geral. É como se o jornal dissesse que novas tecnologias de informação não substituem o primado da imprensa. Ele fala em período de luz e sombras e no fato de alguns filmes de diretores como Woody Allen, Copo- lla e Bergman terem estado em cartaz no final da década de 70 significava o vislumbre do fim do túnel. Ventura diz que nem sempre o diário acertou em suas posições, como o apoio ao golpe de 1964, porque acreditava que a continuidade democrática estava ameaçada e que, enquanto fazia oposição política, continuava apoiando o regime nas diretrizes econômicas. Essa última observação talvez significasse a necessidade de um tom de ponderação no anos 90, como uma forma de afastar uma possível e comercialmente desagradável associação à idéia de jornalismo incendiário, ainda que preservando o legado da imagem de resistência. Duas edições (14 de dezembro de 1968 e 12 de setembro de 1973) são lembradas como monumento à resistência jornalística. A primeira publicada no dia seguinte à decretação do $\mathrm{AI}-5$, quando a redação trabalhou com a presença de cinco censores e, a segunda, quando foi noticiada em primeira página, sem manchete nem foto, o assassinato do presidente chileno Salvador Allende, driblando e ao mesmo tempo acatando a ordem do governo de não publicar nem foto nem manchete sobre o assunto no jornal. As duas edições alimentam até hoje o mito da resistência e a fábula do jornalista esperto contra autoridades ignorantes, sobretudo militares.

É claro que as edições cotidianas dos jornais podem e costumam ser usadas como documentos das épocas em que foram produzidas, onde se pode encontrar tanto discursos explicitamente enunciados quanto rastros daqueles que escreveram, mas também da sociedade na qual estavam inseridos. E, embora cada vez seja menos comum entre historiadores a distinção entre documento e monumento, essas duas edições são celebradas, são rememoradas, justamente a partir de uma intencionalidade monumental atribuída àqueles anos 60/70. O JB dá a entender que elas já foram publicadas na esperança de que fossem, no futuro, celebradas como emblema de circunstâncias profissionais que não deveriam se repetir, como que produzindo um dever de memória nas gerações futuras. (RICOEUR, 2000)

No entanto, é preciso lembrar que foram os editores de 1991 que acionaram essa memória, que ela não brota do passado, mas precisa ser atualizada no presente. $\mathrm{Ou}$ seja, em 1991, essas duas edições mantinham algum valor simbólico no contexto da imprensa fluminense, sobretudo para a história do JB, ainda que, evidentemente, em outro contexto. Segundo o quarto e último artigo, assinado por Léo Schlafman, na página 9, rastros da ditadura avançaram sobre a década de 80 por meio de atitudes anti-democráticas, como a devassa contábil contra o jornal, ordenada pelo presidente José Sarney ("da qual não se recuperou até hoje"), pelo fato de ter apoiado o parlamentarismo, e a ameaça que sofreu por denunciar o esquema de fraude eleitoral da Proconsult em favor de Moreira Franco contra Leonel Brizola. O JB também diz que graças a ele o assassinato de Chico Mendes se tornou escândalo internacional, já que dias antes do crime fora publicada entrevista em que o ambientalista 
revelava os nomes de seus possíveis algozes, em um exercício de previsão. Mas nenhum episódio é lembrado de modo mais significativo que a bomba do Riocentro. O repórter Fritz Utzeri descobriu a farsa da perícia e a versão do suposto atentado subversivo ficou insustentável. Com isso, o JB demonstrou ter ajudado a sufocar o grupo radical militar que rejeitava a abertura política. Assim, o Jornal do Brasil sobe ao palco da História, três décadas depois de a História ter chegado ao Brasil, como dissera Brito sobre os anos 50.

Portanto a edição comemorativa coloca como marco fundamental a reforma dos anos 50. Antes dela, é como a pré-história do jornal. Embora não dê data exata para o início (o ano de 1957 é referido somente uma vez), toda a construção narrativa da edição coloca aquela década como uma espécie de real nascimento do jornal, ou, pelo menos, como um momento em que, pela primeira vez, a história do Brasil e de si próprio podem se afinar. Se a História só chegou ao Brasil nos anos 50 com a industrialização e a economia de mercado, e o JB, entre 60 e 79, foi mais vítima, nos 80 , ele toma a dianteira da história. Sua glória não está no passado distante, mas em um passado recente.

\section{Considerações finais}

Em sua edição centenária, o Jornal do Brasil confeccionou um conjunto de narrativas que, de modo geral, estabeleceram a seguinte relação do diário com o tempo histórico: fundar um periódico no século XIX foi um esforço tremendo, diante do atraso em que o país estava mergulhado técnico-sócio-econônico e politicamente. $\mathrm{O}$ JB funcionou perfeitamente durante mais de 60 anos mas foi somente nos anos 50 que o país lhe ofereceu chance de empreender todo seu potencial a partir da chamada reforma, que impactou todo o jornalismo no país. Finalmente, o jornal poderia deixar sua modernidade latente fluir e transformar o mundo. As décadas seguintes representaram a consolidação da relação do diário com seu público e com o compromisso de intervir na realidade quando julgasse necessário.Diante desse relato, o JB se coloca como ator fundamental dos processos de atualização do fazer jornalístico (e instrumento do fazer histórico), sob a ótica do que há de mais moderno, tendo em vista um permanente aperfeiçoamento sobretudo de natureza polícia. Esse aperfeiçoamento diz respeito a sua crescente capacidade de prever os acontecimentos e, assim, fazer as melhores escolhas no presente. Enquanto outros periódicos destacam em suas comemorações as inovações tecnológicas, o JB acentua seus erros e acertos nas posições que tomou, de modo coerente com o que disse Nascimento Brito: "jornal é de opinião". É muito mais essa possibilidade de se atuar pela expressão que está sendo comemorada em 1991, do que a marcação de uma data monumental em 1891. Até porque a comemoração aí é muito mais um recurso publicitário, para a empresa, a marcação de uma identidade profissional para os jornalista e reafirmação de um pacto com o leitor que uma festa coletiva, celebração pública. Entretanto, essa festa particular do JB, materializada na edição centenária, adquire contornos públicos ao oferecer recursos e suportes de reelaboração não somente da memória do fazer jornalístico como da relação do leitor com seu jornal e da sociedade com seu jornalismo, tendo o JB como paradigma para todos esses fazeres possíveis অFAMEcos

\section{REFERÊNCIAS}

BAKHTIN, Mikhail. Marxismo e filosofia da linguagem. SP: Hucitec, 1992.

BARBOSA, Marialva Carlos. Percursos do olhar. Comunicação, narrativa e memória. Niterói (RJ): EdUFF, 2007.

. Imprensa, Poder e Público: Os diários do Rio de Janeiro (1880-1920). Tese Doutorado História - UFF, 1996.

BERGSON, Henri. Matéria e memória. Ensaio sobre a relação do corpo com o espírito. São Paulo: Martins Fontes, 1999.

COLLINGWOOD, R.G. A idéia de história. Portugal: Editorial Presença, 199?.

FOUCAULT, Michel. O queéum autor? Lisboa: Vega, 2000.

HALBWACHS, Maurice. A memória coletiva. São Paulo: Vértice, Editora Revista dos Tribunais Ltda, 1990.

LE GOFF, Jacques. “Monumento/Documento". In: Enciclopédia Eunandi, vol. 1. Portugal: Imprensa Nacional, 1997, pp. 95-106.

KOSELLECK, Heinhart. Futuro passado. Contribuição àsemântica dos tempos históricos. RJ: Contraponto e PUC-RJ, 2006.

POLLAK, Michael. "Memória, Esquecimento, Silêncio" In: Estudos Históricos 1989/3. Cpdoc/FGV. São Paulo: Editora Revista dos Tribunais Ltda, 1989.

POMIAN, K. L'Ordre du temps. Paris: Gallimard, 1984.

RIBEIRO, Ana Paula Goulart. Imprensa e historia no Rio de Janeiro dos anos 50. Tese Doutorado Comunicação UFRJ, 2000.

RICOEUR, Paul. "O passado tinha um futuro". In: MORIN, Edgar. A religião dos saberes: o desafio do séc. XXI. RJ: Bertrand Brasil, 2001.

. La mèmoire, l'historie, l'obli. Paris: Seuil, 2000.

Tempo e narrativa, tomo I. SP: Papirus, 1994.

SILVA, Marco Antônio Roxo da. Jornalistas, pra quê? Militância sindical e o drama profissional. Tese Doutorado Comunicação - UFF, 2007. 